\title{
RADICAL THACIPR
}

A SOCIALIST, FEMINIST, AND ANTI-RACIST JOURNAL ON THE THEORY AND PRACTICE OF TEACHING

\section{Poetry \\ Two Poems}

by Lucy Arnold

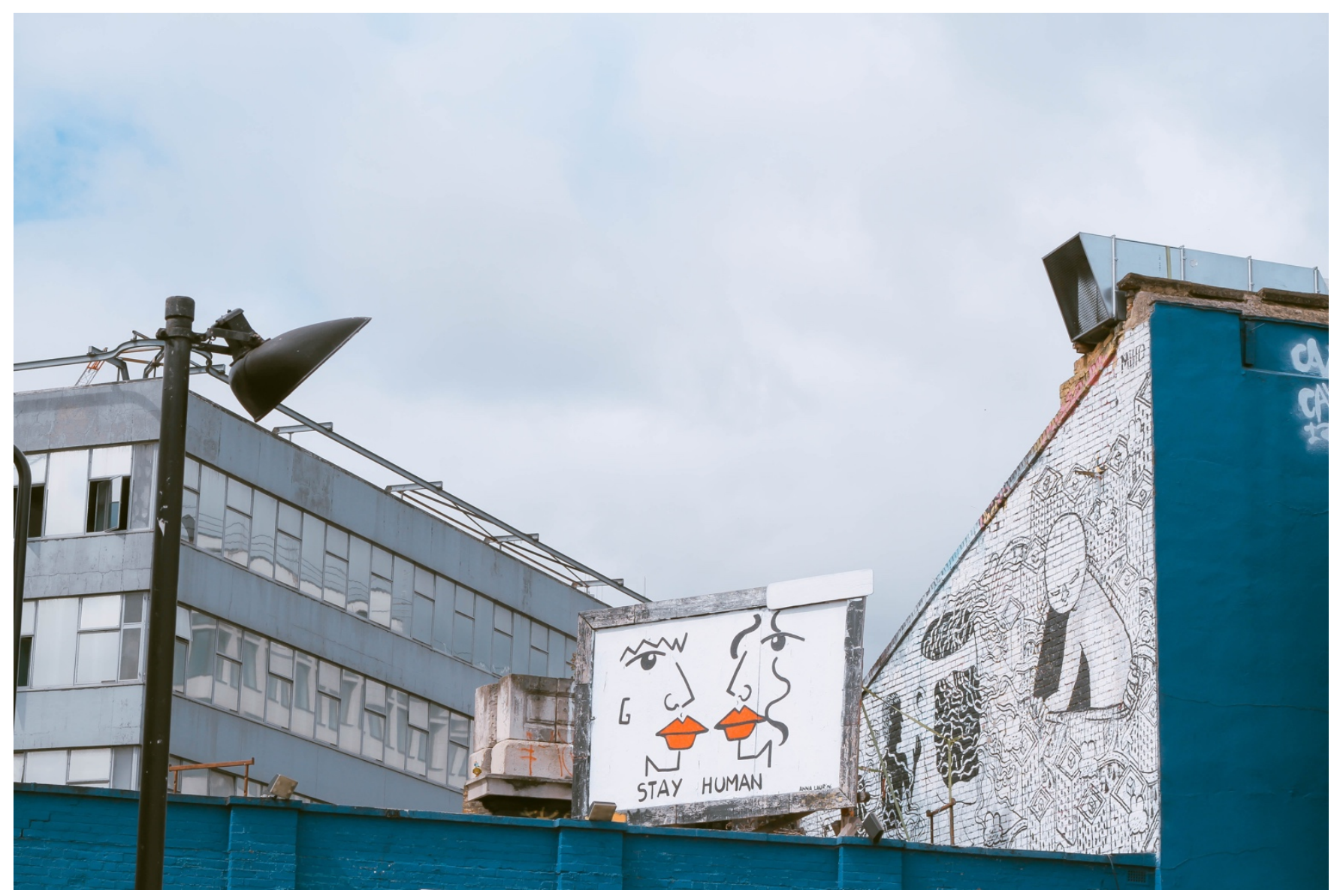




\section{Peace}

i like being up early

before my family stirs

me and the gentle snorts of the coffee machine

and armed men on the street corners 
on receiving an email from a white

woman explaining that she is worried for

her safety following protests on campus

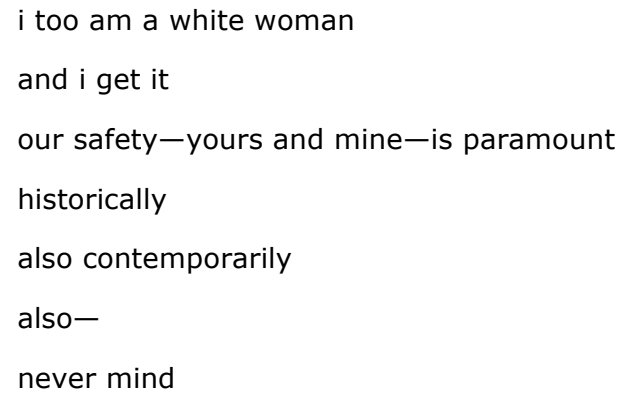




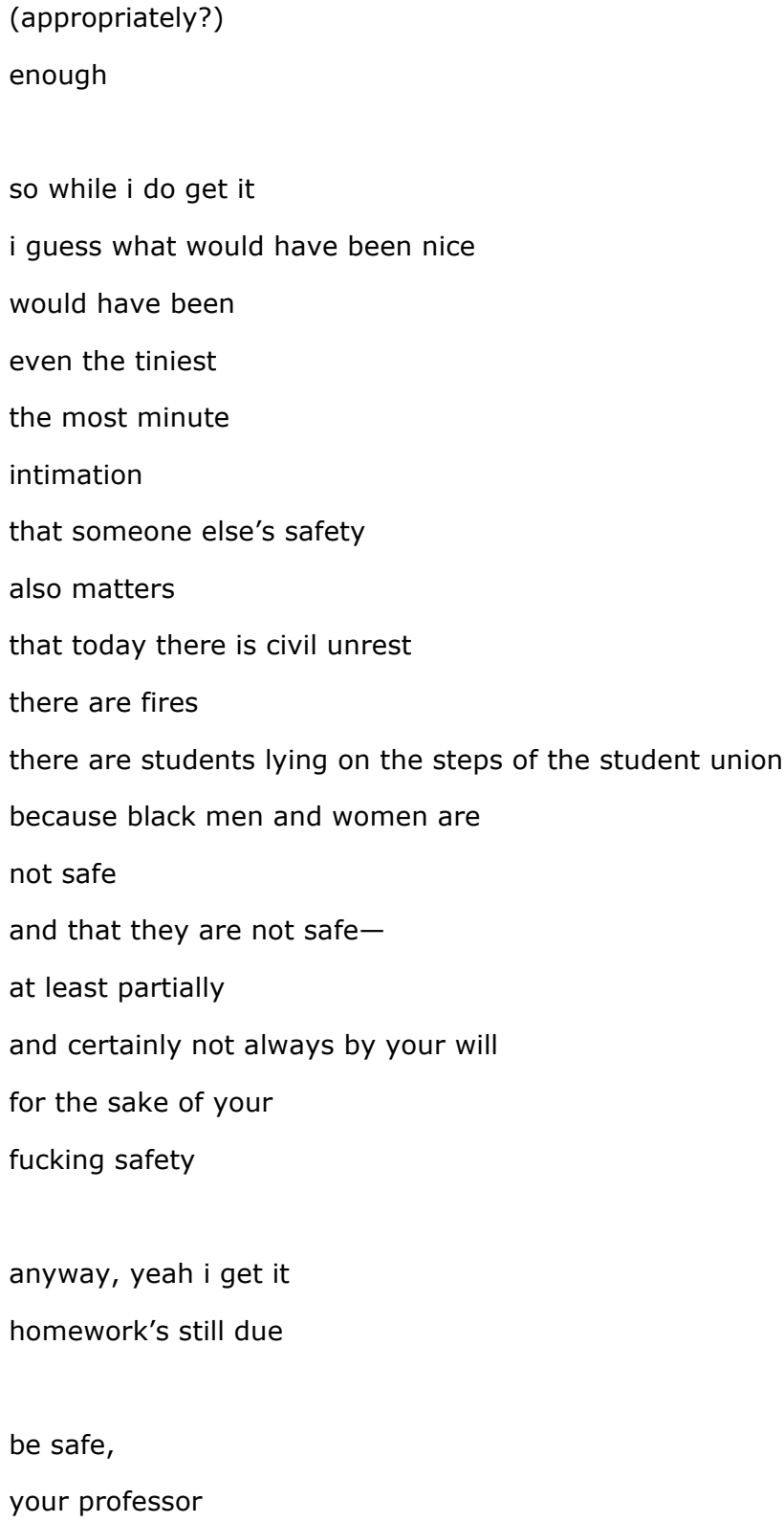

